\title{
Enzymatic Processes Triggered by PEF for Astaxanthin Extraction From Xanthophyllomyces dendrorhous
}

\author{
Diederich Aguilar-Machado 1,2, Carlota Delso', Juan Manuel Martinez', \\ Lourdes Morales-Oyervides ${ }^{3}$, Julio Montañez ${ }^{3}$ and Javier Raso ${ }^{1 *}$ \\ ${ }^{1}$ Food Technology, Facultad de Veterinaria, Universidad de Zaragoza, Zaragoza, Spain, ${ }^{2}$ Department of Food Research, \\ Universidad Autónoma de Coahuila, Saltillo, Mexico, ${ }^{3}$ Department of Chemical Engineering, Universidad Autónoma \\ de Coahuila, Saltillo, Mexico
}

The aim of this study was to evaluate the potential of pulsed electric fields (PEF) to improve the extraction of the lipid-soluble astaxanthin from fresh biomass of a wild-type (CECT 11028) and mutant (ATCC 74219) Xanthophyllomyces dendrorhous strain using ethanol as solvent. Inactivation and propidium uptake studies revealed that inactivation is a good index for estimated the proportion of irreversible permeabilized cells when inactivation is higher than $70 \%$ in the two strains. Ethanol was ineffective for

OPEN ACCESS

Edited by:

Eugene Vorobiev,

University of Technology

of Compiègne, France

Reviewed by:

Noppol-Leksawasdi,

Chiang Mai University, Thailand

Daidi Fan,

Northwest University, China

${ }^{*}$ Correspondence: Javier Raso jraso@unizar.es

Specialty section:

This article was submitted to Bioprocess Engineering,

a section of the journal

Frontiers in Bioengineering and Biotechnology

Received: 15 April 2020 Accepted: 02 July 2020 Published: 29 July 2020

Citation: Aguilar-Machado D, Delso C, Martinez JM, Morales-Oyervides L,

Montañez J and Raso J (2020) Enzymatic Processes Triggered by PEF for Astaxanthin Extraction From Xanthophyllomyces dendrorhous. Front. Bioeng. Biotechnol. 8:857. doi: 10.3389/fbioe.2020.00857 extracting carotenoids from the PEF-treated cells $(20 \mathrm{kV} / \mathrm{cm}, 135 \mu \mathrm{s})$ of the two strains. However, after aqueous incubation of PEF-treated $X$. dendrorhous ATCC 74219 cells for $12 \mathrm{~h}$, up to $2.4 \pm 0.05 \mathrm{mg} / \mathrm{g}$ dried weight (d.w.) of carotenoids were extracted in ethanol. From total carotenoid extracted, around $84 \%$ corresponded to all-trans astaxanthin. The detection and quantification of esterase activity in the supernatant and the relationship between the percentage of esterase activity quantified and the amount of carotenoids extracted indicate that the extraction of astaxanthin was mediated by enzymatic esterase activity triggered by PEF during incubation. On the other hand, the formation of a large lipid globule into the cytoplasm of PEF-treated $X$. dendrorhous CECT 11028 cells during aqueous incubation prevented carotenoid extraction. The process developed in this investigation represents a more sustainable and greener method that those previously used for extracting astaxanthin from yeast.

Keywords: astaxanthin, pulsed electric field, extraction, Xanthophyllomyces dendrorhous, esterase, enzymatic activity

\section{INTRODUCTION}

Astaxanthin (3,3'-dihydroxy- $\beta, \beta$-carotene- $4,4^{\prime}$-dione; $\left.\mathrm{C}_{40} \mathrm{H}_{5} 2 \mathrm{O}_{4}\right)$ is a lipid-soluble oxycarotenoid widely used in food, aquaculture, nutraceutical, cosmetic and pharmaceutical industries due to its relatively high antioxidant activity compared with other antioxidant molecules. It has been reported that astaxanthin has 10 times the antioxidant activity of $\beta$-carotene, 60 times of coenzyme Q10, and 1000 times more antioxidant activity than vitamin E (Higuera-Ciapara et al., 2006; Shah et al., 2016; Zhao et al., 2019). Astaxanthin unique chemical structure makes it a powerful antioxidant with extraordinary biological and physiological properties including cardiovascular disease prevention, strengthening the immune system and anti-tumoral, anti-inflammatory, and anti-diabetes effects (Kurihara et al., 2002; Uchiyama et al., 2002; Ohgami et al., 2003; Pashkow et al., 2008; Nagendraprabhu and Sudhandiran, 2011; Peng et al., 2012; Fakhri et al., 2018). 
Currently, the main use of astaxanthin is as a feed additive for providing the characteristic pink/red color of salmons, trout, and crustaceans. Around $99 \%$ of astaxanthin available in the market is produced synthetically due to their low production cost, high purity, and high stability, and only around 1\% of astaxanthin derived from a natural source. The total astaxanthin production was about 200 tons in 2014 worth 368 million euros and this is expected to encrease double in 2022 (Molino et al., 2018). However, synthetic astaxanthin has not been approved for human consumption by safety concerns related to the use of petrochemicals during its synthesis process (Li et al., 2011; Shah et al., 2016). On the other hand, natural astaxanthin has gained huge attention from researches and consumers in the last years. Studies have suggested that natural astaxanthin has around 20 times more antioxidant activity compared with the synthetic molecule (Capelli et al., 2013). The growing demand from industries and consumers has encouraged researches to demonstrate the feasibility of astaxanthin production and extraction from diverse natural sources.

The yeast Xanthophyllomyces dendrorhous is considered one of the most important sources of natural astaxanthin because around $84 \%$ of the total carotenoids that it synthesizes correspond to these compound (Stoklosa et al., 2018). Astaxanthin is formed as different geometrical isomers with cis and trans double bonds in the polyene chain. The yeast $X$. dendrorhous synthesize the all-trans isomer mainly, but the 9-cis and 13-cis isomers can be also found (Schmidt et al., 2011). The high-rate cell growth with short cultivation cycles, the ability to metabolize waste-based culture media, no seasonal conditions constraints and the easy manipulation of culture conditions to improve yields make the yeast $X$. dendrorhous an alternative for large scale production of natural astaxanthin (Wu et al., 2018; Villegas-Méndez et al., 2019). Generally astaxanthin production from naturally isolated strains of $X$. dendrorhous is very low (between 200 and $400 \mu \mathrm{g} / \mathrm{g}$ ), however, some authors have developed genetic manipulations to get hyper-producer strains with yields up to 10-fold higher than the wild-type strains (Visser et al., 2003; Zhuang et al., 2020).

Xanthophyllomyces dendrorhous accumulates astaxanthin in the cytoplasm in the form of droplets associated with the cytoplasmatic membrane and fatty acids (Johnson and Gil-Hwan, 1991; Jacobson et al., 1995; Urnau et al., 2018). The presence of a thick, rigid and indigestible cell envelope, as well as the lipophilic nature of astaxanthin, are the biggest challenges in the development of efficient methodologies for extraction of this compound (Gogate and Nadar, 2015). Over the last years, several cell wall disruption processes such as chemical (acid extraction), enzymatic and physical or mechanical (ultrasound, microwave, high-pressure homogenization) methods have been evaluated to facilitate the recovery of intracellular carotenoids from X. dendrorhous (Choi et al., 2007; Ni et al., 2008; Michelon et al., 2012; Gogate and Nadar, 2015; Hasan et al., 2016; Urnau et al., 2018; Zhuang et al., 2020). However, those techniques present some disadvantages such as high implementation costs, long extraction time, excessive cell destruction and high cost of purification of the target molecule (Martínez et al., 2018). Furthermore, most carotenoids extraction techniques require the drying of biomass with subsequent extraction with a large amount of organic solvent. Therefore, it is desirable to develop efficient extraction methods from wet biomass using green solvents in order to achieve economical and eco-friendly processes (Martínez et al., 2019).

Pulsed electric fields (PEF) is a technique that consists in the application of an external electric field to induce the permeabilization (electroporation) of biological membranes (Kotnik et al., 2015). In contrast to other technologies that cause cell disruption, energetic requirements of PEF are low, it is easily scalable, does not result in cell disintegration, minimizing the release of cell debris and facilitating purification of the extracted compound (Kotnik et al., 2015).

Several studies have demonstrated that electroporation by PEF improve the extraction of intracellular components such as proteins, lipids, and pigments from microorganisms has been reported (Ganeva et al., 2003; Chittapun et al., 2020; Leonhardt et al., 2020). Very recently, it has been proposed that PEF not only permeabilized the cytoplasmatic membrane to enable the release of intracellular biomolecules but also trigger some enzymatic process that accelerates the autolysis and the subsequent release of intracellular components (Martínez et al., 2018, 2019; Silve et al., 2018; Scherer et al., 2019). The application of PEF technology on the recovery of intra-cellular carotenoids from $X$. dendrorhous has not been reported.

This study aimed to evaluate the effect of PEF-assisted on the extraction of astaxanthin from fresh biomass of a wildtype and a mutant hyper-producer $X$. dendrorhous strain using ethanol as solvent.

\section{MATERIALS AND METHODS}

\section{Yeast Strains and Culture Conditions}

The wild-type $X$. dendrorhous CECT 11028 and the mutant hyper-producer $X$. dendrorhous ATCC 74219 strains were obtained from the Colección Española de Cultivos Tipo (CECT) and the American Type Culture Collection (ATCC, Beltsville, $\mathrm{MD}$, United States), respectively. The microorganisms were maintained in cryovials at $-80^{\circ} \mathrm{C}$. Yeasts were grown in $500 \mathrm{~mL}$ glass flask containing $250 \mathrm{~mL}$ of Potato-Dextrose Broth (PDB, Oxoid, Basingstoke, United Kingdom) for 6 days in a rotatory shaker (Heidolph Unimax 1010, Germany) at $200 \mathrm{rpm}$ and $25^{\circ} \mathrm{C}$. The inoculum was around $10^{6}$ cells $/ \mathrm{mL}$ defined by Thoma counting chamber.

Yeast growth was monitored by measuring the cell density at $600 \mathrm{~nm}$ and the cell number by the plate-counting method (PDA, Oxoid, Basingstoke, United Kingdom). Incubation time needed to obtain the maximum carotenoid production was established by determining the carotenoid production during the cultivation period using the dimethyl sulfoxide method as described below.

\section{PEF Treatments}

Pulsed electric fields unit (Modulator PG, ScandiNova, Uppsala, Sweden) used in this investigation was previously described by Saldaña et al. (2010). Before the treatments, fresh biomass of $X$. dendrorhous CECT 11028 and X. dendrorhous ATCC 74219 
were centrifuged (Heraeus Megafuge 1.0R, United Kingdom) at $3000 \times g$ for $5 \mathrm{~min}$ at $4^{\circ} \mathrm{C}$. Next, the pellet was resuspended in a citrate-phosphate McIlvaine buffer $(\mathrm{pH} 7.0,1 \mathrm{mS} / \mathrm{cm})$ to a final concentration of approximately $10^{8} \mathrm{cell} / \mathrm{mL}$. The cell suspension $(0.5 \mathrm{~mL})$ of each strain was deposited in a static parallel-electrode tempered chamber $\left(25 \pm 1^{\circ} \mathrm{C}\right)$ with a gap of $0.25 \mathrm{~cm}$ and a radius of $0.8 \mathrm{~cm}$ employing a $1 \mathrm{~mL}$ sterile syringe (TERUMO, Leuven, Belgium). The cell suspension was subjected to PEF treatment of 10-60 monopolar square pulses of $3 \mu$ s pulses at electric field strength between 10 and $25 \mathrm{kV} / \mathrm{cm}$ at $0.5 \mathrm{~Hz}$.

\section{PEF Treatment Intensity Effect on Cell Inactivation and Irreversible Permeabilization}

PEF treatment intensity was evaluated between 10 to $25 \mathrm{kV} / \mathrm{cm}$ at $0.5 \mathrm{~Hz}$ frequency. The specific energy applied during treatments ranged from 3.0 to $114.3 \mathrm{~kJ} / \mathrm{kg}$, corresponding to the minimum and maximum treatment intensity applied, respectively.

After PEF treatment, cells were plated in PDA and incubated at $25^{\circ} \mathrm{C}$ for $72 \mathrm{~h}$. The inactivation degree was expressed as the logarithmic ratio of the initial number $\left(\mathrm{N}_{\mathrm{O}}\right)$ of cells and the number of survivors $\left(\mathrm{N}_{\mathrm{t}}\right)$ after different PEF treatments.

The irreversible permeabilization after PEF treatments was quantified by propidium iodide uptake technique (GarcíaGonzalo and Pagán, 2017). PEF-treated and untreated cells were stained after $1 \mathrm{~h}$ of the PEF treatments. $50 \mu \mathrm{L}$ of PI $(0.1 \mathrm{mg} / \mathrm{mL})$ was added to $450 \mu \mathrm{L}$ of yeast cell suspension and incubated under dark conditions for $5 \mathrm{~min}$. Then, the cells were centrifugated and washed with $450 \mu \mathrm{L}$ of phosphate-buffered saline (PBS) solution of $\mathrm{pH} 7.4$ to remove the extracellular PI remained. This procedure was repeated three times.

\section{PEF Treatment Intensity Effect on Carotenoid Extraction}

Non-treated or PEF-treated yeast suspensions $\left(10^{8}\right.$ cell $\left./ \mathrm{mL}\right)$ either immediately after PEF treatment or after an incubation process ranging from 3 to $24 \mathrm{~h}$ at $25^{\circ} \mathrm{C}$ in a buffer solution of $\mathrm{pH}$ 7.0 were centrifuged at $3,000 \times g$ for $5 \mathrm{~min}$ and re-suspended in ethanol at $96 \%$ for $12 \mathrm{~h}$. After incubation, total carotenoids were quantified following the methodology described below.

After selecting the required incubation time in the buffer solution of $\mathrm{pH} \mathrm{7.0,} \mathrm{the} \mathrm{kinetics} \mathrm{of} \mathrm{carotenoids} \mathrm{extraction} \mathrm{were}$ evaluated for non-treated and PEF-treated cells at different electric field strengths $(10,15,20$, and $25 \mathrm{kV} / \mathrm{cm}$ for $135 \mu \mathrm{s})$.

\section{Evaluation of the Enzymatic Activity in the Supernatant Containing Yeast}

Enzymatic activity was evaluated in the supernatant of PEFtreated cells during the incubation in buffer solution. Untreated cells were used as control. Then, enzymatic thermal inactivation and its effect on carotenoids extraction were also assessed.

\section{$\beta$-Glucanase Activity Measurement}

$\beta$-glucanase activity (EC 3.2.1.6) in the supernatant of PEFtreated and untreated cells was conducted using the Megazyme Azo-barley $\beta$-glucan method (malt and bacterial $\beta$-glucanase and cellulase assay procedure, Megazyme, Ireland). Aliquots of $0.05 \mathrm{~mL}$ of Azo-Barley glucan substrate solution (pre-heated at $30^{\circ} \mathrm{C}$ ) were dispensed into centrifuge tubes and incubated at $30^{\circ} \mathrm{C}$ for $5 \mathrm{~min}$. After that, $1 \mathrm{~mL}$ of the supernatant of each yeast suspension was mixed with the pre-heated glucan substrate and incubated at $30^{\circ} \mathrm{C}$ for $10 \mathrm{~min}$. After incubation, $3 \mathrm{~mL}$ of the precipitant solution $\left[30.0 \mathrm{~g}\right.$ of $\mathrm{C}_{2} \mathrm{H}_{3} \mathrm{NaO}_{2}$ and $3.0 \mathrm{~g}$ of $\mathrm{ZnC}_{4} \mathrm{H}_{6} \mathrm{O}_{4}$ in $1 \mathrm{~L}$ of ethanol $(66.5 \%)$, methanol $(3.5 \%)$ and water $(30 \%)]$ were added and stirred vigorously. Tubes were stored at room temperature for $5 \mathrm{~min}$, stirred and centrifuged $(1000 \times \mathrm{g}, 10 \mathrm{~min})$. Finally, absorbance at $590 \mathrm{~nm}$ of the supernatant of each sample was read against distilled water. With each set of determinations, a reaction blank was included. Enzymatic activity was calculated by correlating the malt $\beta$-glucanase standard curve on Azo Barley Glucan and absorbance from each sample.

\section{Esterase Activity Measurement}

The measurement of esterase enzymatic activity (EC 3.1.1.1) of supernatant of PEF-treated and untreated cells was performed with the colorimetric p-nitrophenyl chromogenic assay (Gilham and Lehner, 2005). For analysis, a stock solution of $250 \mathrm{mM}$ of $p$-nitrophenyl-acetate dissolved in dichloromethane $\left(\mathrm{Cl}_{2} \mathrm{CH}_{2}\right)$ was prepared. Immediately before determination, $20 \mu \mathrm{L}$ of stock solution was diluted in $10 \mathrm{~mL}$ of a McIlwaine buffer $(\mathrm{pH} 8.0$ and conductivity of $1 \mathrm{mS} / \mathrm{cm}$ ). Then, $100 \mu \mathrm{L}$ of the supernatant of each incubation time was added and vortexed with $1 \mathrm{~mL}$ of $p$-nitrophenyl-acetate solution in glass tubes and incubated at $37^{\circ} \mathrm{C}$ for $30 \mathrm{~min}$. The liberation of p-nitrophenol was proportional to esterase activity measured spectrophotometrically at $410 \mathrm{~nm}$. Distilled water was used as a blank.

\section{Esterase Thermal Inactivation and Release of Carotenoids From Yeast}

A suspension of PEF-treated cells $(20 \mathrm{kV} / \mathrm{cm}$ and $135 \mu \mathrm{s})$ was heat-treated at 50 and $60^{\circ} \mathrm{C} \pm 1{ }^{\circ} \mathrm{C}$ for $5 \mathrm{~min}$ and incubated in a buffer solution of $\mathrm{pH} 7.0$ for $12 \mathrm{~h}$ at $25^{\circ} \mathrm{C}$. Preliminary experiments were conducted to define the temperatures levels required to inactivate esterase without affecting astaxanthin. After incubation, unheated and heattreated PEF-treated cells were centrifugated and suspended in ethanol for carotenoids extraction during $24 \mathrm{~h}$. The supernatant was analyzed to determine the amount of the esterase activity remaining after incubation. The percentage of esterase activity remained in the heat-treated samples was calculated according to the maximum esterase activity quantified in the unheated PEF-treated cell suspension after $12 \mathrm{~h}$ of incubation.

\section{Analytical Methods}

Total carotenoids were recovered and quantified following the methodology described by Sedmak et al. (1990). $0.5 \mathrm{~mL}$ of Dimethyl sulfoxide (DMSO) was added to $1.0 \mathrm{~mL}$ of biomass previously centrifugated. Then $0.2 \mathrm{~mL}$ of $0.01 \mathrm{M}$ sodium phosphate and $2.0 \mathrm{~mL}$ of hexane: ethyl acetate (1:1) was added and vortexed for $5 \mathrm{~min}$. The samples were then centrifugated for $5 \mathrm{~min}$ at $10,000 \times g$ to separate the organic phase. Carotenoids concentration was quantified spectrophotometrically for DMSO 
extraction and PEF assisted extraction. The total carotenoid yield was calculated using the equation:

$$
Y x=\frac{V^{*} A^{*} 10^{6}}{E^{1 \% *} 100^{*} M}
$$

where Yx represents the carotenoid yield (mg/g d.w.); A is the absorbance at $480 \mathrm{~nm} ; \mathrm{V}$ the volume of solvent used $(\mathrm{mL})$; $\mathrm{M}$ the dry cell mass ( $\mathrm{g}$ ) and $\mathrm{E}^{1 \%}$ the specific absorptivity of solvent (2100).

For HPLC analysis, the ethanolic extract of each sample was previously evaporated in a vacuum concentrator and then resuspended in methanol/dichloromethane $(3: 1, v / v)$ for subsequent injection. Astaxanthin quantification was performed according to the method described by Yuan and Chen (1997). HPLC analysis was performed on a Varian ProStar highperformance liquid chromatograph equipped with a ProStar 240 ternary pump, an automatic ProStar 410 autosampler and a ProStar 335 photodiode array detector. The separation was performed using a reverse-phase column (LC Luna ${ }^{\circledR}$ $100 \AA$ C18 $250 \times 4.6 \mathrm{~mm} ; 5 \mu \mathrm{m}$ particle size, Phenomenex, United States) with a pre-column (LC Luna $50 \times 4.6 \mathrm{~mm}$; $5 \mu \mathrm{m}$ particle size, Phenomenex, United States). A single mobile phase of methanol/dichloromethane/water (80.5:17:2.5, by volume) was used during analysis. The flow rate was $1.0 \mathrm{~mL} / \mathrm{min}$ with a pre-conditioned sample at $25^{\circ} \mathrm{C}$. Transastaxanthin concentration was determinate by comparing the time retention of a commercial standard of transastaxanthin (Sigma, St Louis, MO, United States) with each sample analyzed.

\section{Statistical Analysis}

All experiments were performed in triplicate and presented as the average value \pm standard deviation (SD). The differences were considered significant to $p<0.05$. One-way analysis of variance (ANOVA) and Tukey test were used to determine the significant differences between treatment using Statistica 7.0 (Statsoft, Tulsa, OK, United States).

\section{RESULTS}

\section{Sensitivity of $X$. dendrorhous CECT 11028 and $X$. dendrorhous ATCC ${ }^{\circledR}$ $74219^{\mathrm{TM}}$ to Pulsed Electric Field Treatments}

The inactivation by PEF treatments of the two $X$. dendrorhous strains used in this study (CECT 11028 and ATCC 74219) varying electric field strength and treatment time is shown in Figures 1A,B, respectively. It can be seen that the inactivation increased with the electric field strength and treatment time above the electric field threshold that was 10 and $15 \mathrm{kV} / \mathrm{cm}$ for the strains CECT 11028 and ATCC 74219, respectively. X. dendrorhous ATCC 74219 presented higher resistance to PEF inactivation compared to $X$. dendrorhous CECT 11028 under the most intense treatment mainly. For example, while 1.6, 2.55 and $2.56 \log _{10}$ cycles of inactivation were observed after 15 ,
20 and $25 \mathrm{kV} / \mathrm{cm}$ and $180 \mu \mathrm{s}$ for the CECT 11028 strain, an inactivation of $0.61,0.81$ and $1.25 \log 10$ cycles was obtained for $X$. dendrorhous ATCC 74219.

It is well-known that one of the effects of PEF is the loss of the selective permeability of the cell membranes as a consequence of the electroporation. Irreversible electroporation allows the uncontrolled pass of ions and macromolecules through the cell membranes leading to microbial inactivation by loss of the cellular homeostasis. Figure 2 shows the relationship between the percentage of inactivated and irreversible permeabilized cells after the application of PEF at different intensities $(10-25 \mathrm{kV} / \mathrm{cm})$ for both strains (PI results can be viewed in the Appendix Figure A1). For both microorganisms, a good correlation between irreversible electroporation and inactivation was observed when the percentage of cell death was higher than $70 \%$. On the other hand, a higher percentage of inactivated cells compared to PI permeabilized cells were observed when the inactivation was below this value. The lack of correlation between the percentage of dead and permeabilized cells when the inactivation effect was low could indicate that a certain number of inactivated cells were able to recover the integrity of their membrane even after losing their viability (García et al., 2007; Luengo et al., 2014; Martínez et al., 2018). Therefore, this proportion of inactivated cells would behave just like those non-electroporated cells during the extraction of intracellular compounds.

\section{Carotenoid Extraction of Xanthophyllomyces Strains Assisted by PEF}

According to the data obtained from the inactivation and permeabilization, a PEF treatment at $20 \mathrm{kV} / \mathrm{cm}$ for $135 \mu \mathrm{s}$ that corresponds to a total specific energy of $54 \mathrm{~kJ} / \mathrm{kg}$ was then selected to evaluate the effect of PEF in the carotenoids extraction from the two $X$ dendrorhous strains. This PEF treatment resulted in an inactivation/permeabilization of around $80 \%$ in the cell population of the two strains.

Preliminary studies showed that when both untreated and PEF-treated cells were immediately suspended in ethanol, the presence of carotenoids in the extraction medium was deficient even after $48 \mathrm{~h}$ of incubation.

Then, the influence of the incubation time in a buffer solution ( $\mathrm{pH}$ 7.0) before the extraction with ethanol was evaluated on untreated and PEF-treated cells of both $X$. dendrorhous strains. The results are shown in Figure 3. It can be observed that the incubation in the buffer solution was ineffective for extracting carotenoids in the PEF-treated cells of CECT 11028 strain and untreated cells of both strains. For such cases, extracted carotenoids never reached values over $0.25 \pm 0.01 \mathrm{mg} / \mathrm{g}$ d.w. throughout all evaluated incubation time. Nevertheless, mutant PEF-treated cells resulted in a subsequent extraction yield of $0.88 \pm 0.10 \mathrm{mg} / \mathrm{g}$ d.w. after $3 \mathrm{~h}$ of incubation, reaching a maximum value after $12 \mathrm{~h}$ of incubation $(1.9 \pm 0.18 \mathrm{mg} / \mathrm{g}$ d.w.). Extraction yields obtained at $24 \mathrm{~h}$ of incubation were not significantly different from those obtained at $12 \mathrm{~h}(p<0.05)$. The extraction achieved after $12 \mathrm{~h}$ of incubation represented an improvement 

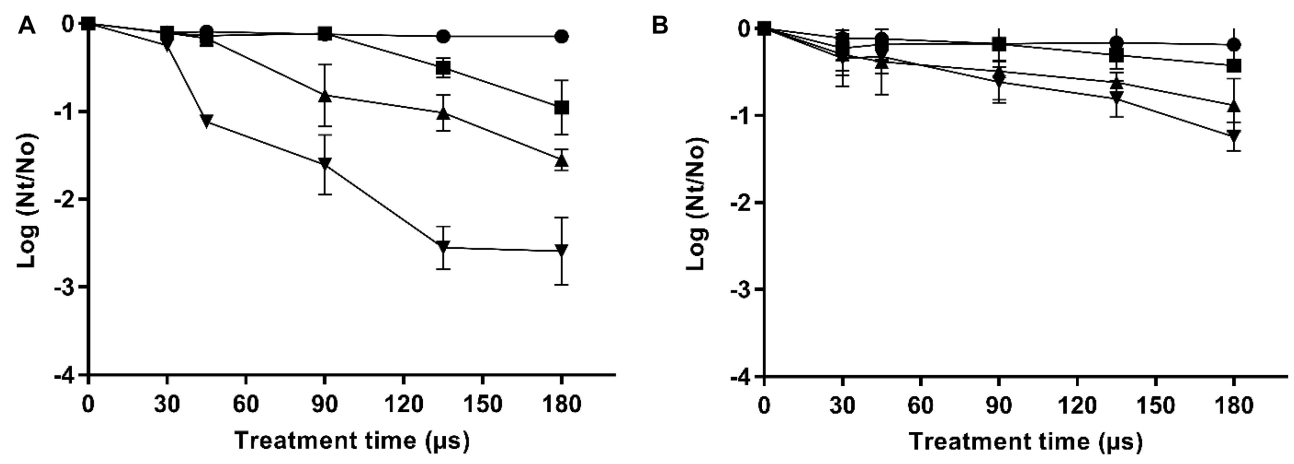

FIGURE 1 | Inactivation curves of $X$. dendrorhous CECT 11028 (A) and X. dendrorhous ATCC 74219 (B) by PEF at different electric fields strength. $10 \mathrm{kV} / \mathrm{cm}(\mathbf{})$, $15 \mathrm{kV} / \mathrm{cm}(\mathbf{\square}), 20 \mathrm{kV} / \mathrm{cm}(\mathbf{\Delta}), 25 \mathrm{kV} / \mathrm{cm}(\mathbf{v})$.

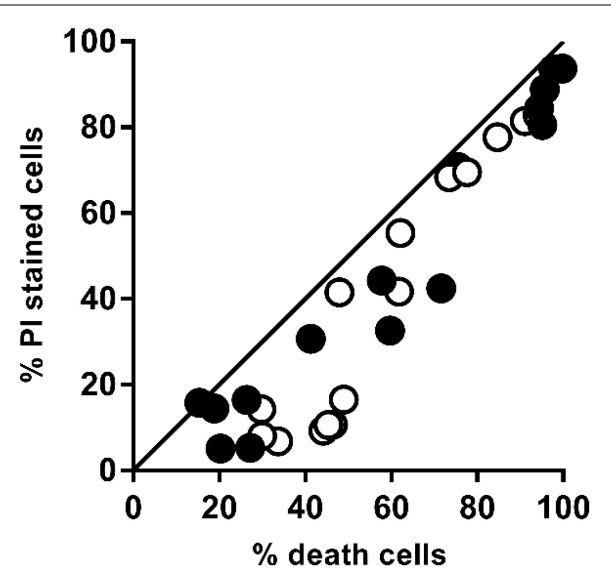

FIGURE 2 | Relationship between the percentage of irreversible permeabilized cells and the percentage of dead cells of $X$. dendrorhous CECT 11028 ( ) and $X$. dendrorhous ATCC $74219(\bigcirc)$ after applied PEF treatments shown in Figure 1. The straight line with slope 1 and intercept 0 represents a perfect agreement between the percentage of Pl uptake and cell death.

of more than twice the extraction yield achieved at the first $3 \mathrm{~h}$ of incubation and around 9.5-fold compared with untreated samples.

Since only the pre-treatment by PEF for carotenoids extraction was effective for $X$. dendrorhous ATCC 74219, only this strain was selected for subsequent studies in this section. Thereafter, the intensity of the PEF treatment and extraction time in ethanol effect on the carotenoids recovery yield was evaluated. The incubation time in buffer was kept at $12 \mathrm{~h}$ for such studies.

The extraction kinetics in ethanol of carotenoids from untreated and PEF-treated cells at different pulsed electric field strength $(135 \mu \mathrm{s})$ are shown in Figure 4. Untreated cells and PEF-treated with the lowest applied electric field $(10 \mathrm{kV} / \mathrm{cm})$ resulted in poor extraction yields. However, significant extraction levels were obtained at electric field strength equal to or higher than $15 \mathrm{kV} / \mathrm{cm}$. These results confirmed that it was required the irreversible electroporation of the cell membranes to be able to improve carotenoids yields from fresh biomass of $X$. dendrorhous

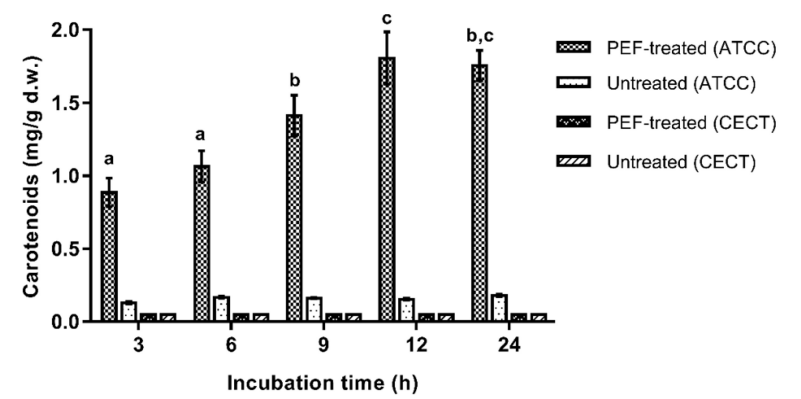

FIGURE 3 | Influence of the incubation time in buffer of $\mathrm{pH} 7.0$ on the extracted carotenoids in ethanol for $12 \mathrm{~h}$ from untreated and PEF treated cells of $X$. dendrorhous CECT 11028 and X. dendrorhous ATCC 74219. Different letter indicates significant statistical differences $(p<0.05)$.

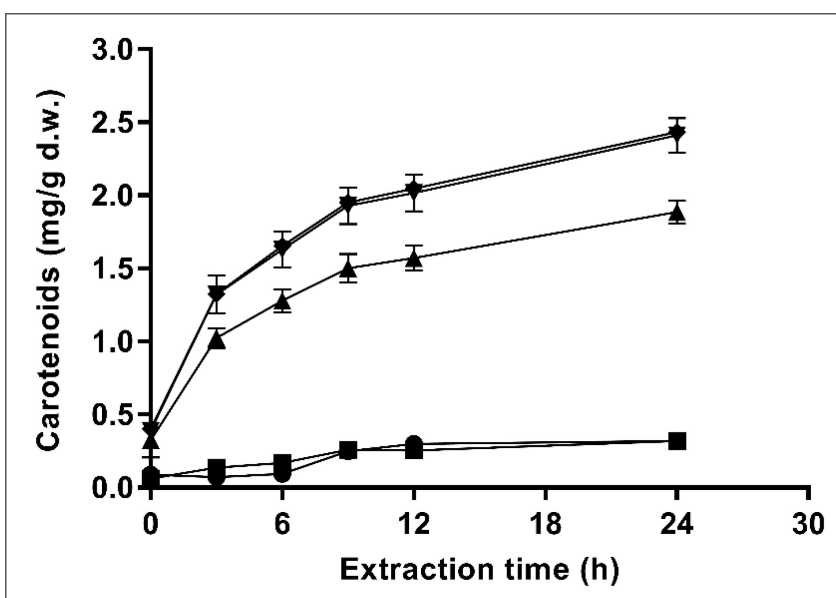

FIGURE 4 | Effect of the electric field strength on ethanolic extraction kinetics of carotenoids from and $X$. dendrorhous ATCC 74219 after $12 \mathrm{~h}$ of incubation in buffer of pH 7.0: $10 \mathrm{kV} / \mathrm{cm}(\boldsymbol{\square}), 15 \mathrm{kV} / \mathrm{cm}(\boldsymbol{\Delta}), 20 \mathrm{kV} / \mathrm{cm}(\boldsymbol{\nabla}), 25 \mathrm{kV} / \mathrm{cm}(\boldsymbol{\vee})$, and untreated (0)

ATCC 74219 after buffer incubation. On the other hand, an increment in the electric field strength from 20 to $25 \mathrm{kV} / \mathrm{cm}$ did not significantly affect the extraction yield, supporting the 
TABLE 1 | Astaxanthin quantification by HPLC of ethanolic carotenoid extracts obtained from PEF-treated cells of X. dendrorhous ATCC 74219 at different treatment intensities and specific energy applied after $12 \mathrm{~h}$ of incubation in buffer of $\mathrm{pH} 7.0$.

\begin{tabular}{|c|c|c|c|c|c|}
\hline Electric field strength $(\mathrm{kV} / \mathrm{cm})$ & $\begin{array}{l}\text { Energy applied } \\
\text { (KJ/kg) }\end{array}$ & $\begin{array}{c}\text { Yield, } \\
\text { carotenoids } \\
(\mathrm{mg} / \mathrm{g})\end{array}$ & Extractability (\%) & $\begin{array}{c}\text { Yield, trans } \\
\text { astaxanthin } \\
(\mathrm{mg} / \mathrm{g})\end{array}$ & $\begin{array}{c}\text { Trans- } \\
\text { astaxanthin } \\
(\%)\end{array}$ \\
\hline 10.00 & 13.50 & $0.32 \pm 0.02^{a}$ & $9 \pm 0.54^{a}$ & $0.32 \pm 0.05^{a}$ & $100 \pm 0.0^{\mathrm{a}}$ \\
\hline 15.00 & 31.20 & $1.89 \pm 0.08^{b}$ & $54 \pm 2.24^{b}$ & $1.54 \pm 0.17^{b}$ & $82 \pm 0.84^{b}$ \\
\hline 20.00 & 54.00 & $2.41 \pm 0.12^{\mathrm{c}}$ & $69 \pm 3.37^{c}$ & $1.92 \pm 0.01^{\mathrm{c}}$ & $80 \pm 0.38^{c}$ \\
\hline 25.00 & 85.73 & $2.43 \pm 0.05^{\mathrm{c}}$ & $70 \pm 1.29^{c}$ & $2.06 \pm 0.02^{\mathrm{c}}$ & $84 \pm 0.38^{c}$ \\
\hline Control & & $0.32 \pm 0.02^{a}$ & $9 \pm 0.54^{a}$ & & \\
\hline Total carotenoids (DMSO) & & $3.50 \pm 0.15^{d}$ & $100 \pm 0.0^{d}$ & $2.81 \pm 0.18^{d}$ & $80 \pm 1.69^{d}$ \\
\hline
\end{tabular}

Results are the average values of three independents experiments (mean \pm standard deviation). ${ }^{a-d}$ Different letter indicates significant statistical differences ( $\left.p<0.05\right)$.

fact that no statistically significant differences in the number of inactivated cells were observed at this electric field strength levels during $135 \mu$ s (Figure 1B).

Additionally, the extraction pattern depicted in Figure 4 shows a typical profile for solid-liquid extraction processes. The highest extraction rate was observed during the first $9 \mathrm{~h}$ of the process (around $80 \%$ of the total carotenoids were extracted). Then, the equilibrium seems to be reached at a lower rate.

The carotenoid extractability and trans-astaxanthin yields and the trans-astaxanthin percentage of recovered carotenoids obtained at each evaluated electric field strength levels after $12 \mathrm{~h}$ of buffer incubation and $24 \mathrm{~h}$ extraction with ethanol are shown in Table 1. Results for untreated samples (control), total carotenoids (extracted with DMSO) and the total specific energy applied at each electric field strength level are also shown. Total carotenoid yield recovered with the conventional method (DMSO) was $3.50 \pm 0.15 \mathrm{mg} / \mathrm{g}$ d.w. Carotenoids yields ranged between $0.32 \pm 0.02$ and $2.43 \pm 0.05 \mathrm{mg} / \mathrm{g}$ d.w. for PEFtreated cells, which corresponded to $9-70 \%$ of extractability. The carotenoid yield obtained with the control (untreated/ethanol) was $0.32 \pm 0.02 \mathrm{mg} / \mathrm{g}$ d.w. (9\% extractability). Thus, there was not a significant difference between the control and PEF-treated cells with an electric field level of $10 \mathrm{kV} / \mathrm{cm}$. The highest carotenoid extraction yield was observed by applying an electric field strength in the range of $20-25 \mathrm{kV} / \mathrm{cm}$ and $135 \mu \mathrm{s}$, representing an extractability value of $70 \%$ of total carotenoids contained in the yeast suspension. However, at $20 \mathrm{kV} / \mathrm{cm}$ implies that $37 \%$ less energy is required in comparison with treatment at $25 \mathrm{kV} / \mathrm{cm}$.

HPLC analysis of the carotenoid extracts showed that from the recovered carotenoids, $80-84 \%$ corresponded to transastaxanthin for PEF-treated samples (Table 1). Similar\% transastaxanthin was obtained for the total carotenoids extracted with DMSO (80\%).

\section{Understanding Mechanism Involved in the Extraction Assisted by PEF of Carotenoid From Xanthophyllomyces Strains}

After demonstrating the efficacy of ethanol for extracting large amounts of carotenoids from PEF-treated $X$. dendrorhous ATCC 74219 previously incubated in a buffer $(\mathrm{pH}=7.0)$, studies

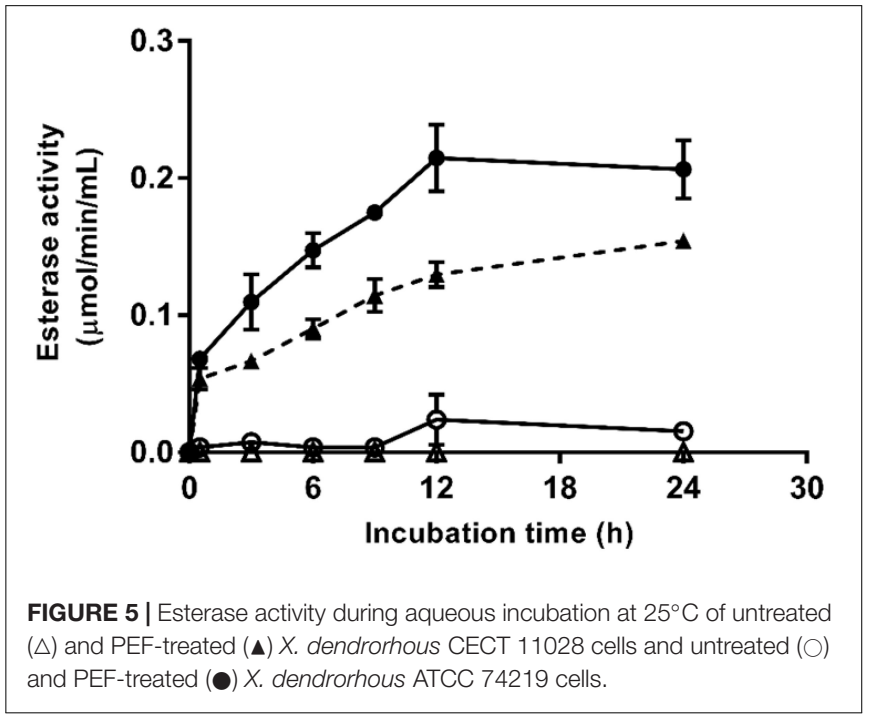

were conducted in order to get an insight into the mechanisms involved and to be able to explain the inefficiency of PEFtreatment on the wild strain.

In order to verify if the PEF treatment triggered an enzymatic process that enabled the carotenoid extraction of $X$. dendrorhous, the $\beta$-glucanase and esterase activities were measured during the incubation of the untreated and PEF-treated cells $(20 \mathrm{kV} / \mathrm{cm}$ and $135 \mu \mathrm{s})$ in a buffer of $\mathrm{pH} 7$.

The $\beta$-glucanase activity was not detected in the supernatant of the suspension containing untreated or PEF-treated cells of both $X$. dendrorhous strains after $12 \mathrm{~h}$ of incubation at $25^{\circ} \mathrm{C}$ (data not showed).

Enzymatic esterase activity during aqueous incubation at $25^{\circ} \mathrm{C}$ of untreated and PEF-treated X. dendrorhous ATCC 74219 and CECT 11028 cells are shown in Figure 5. Esterase activity in the media containing untreated cells was negligible even after $24 \mathrm{~h}$ of incubation. In contrast, esterase activity in the media containing PEF-treated cells of both $X$. dendrorhous strains increased along the time, reaching the maximum activity and equilibrium after $12 \mathrm{~h}$ of aqueous incubation, approximately. Such results suggested that the enzyme esterase was released from the cytoplasm of the treated cells as consequence of the 

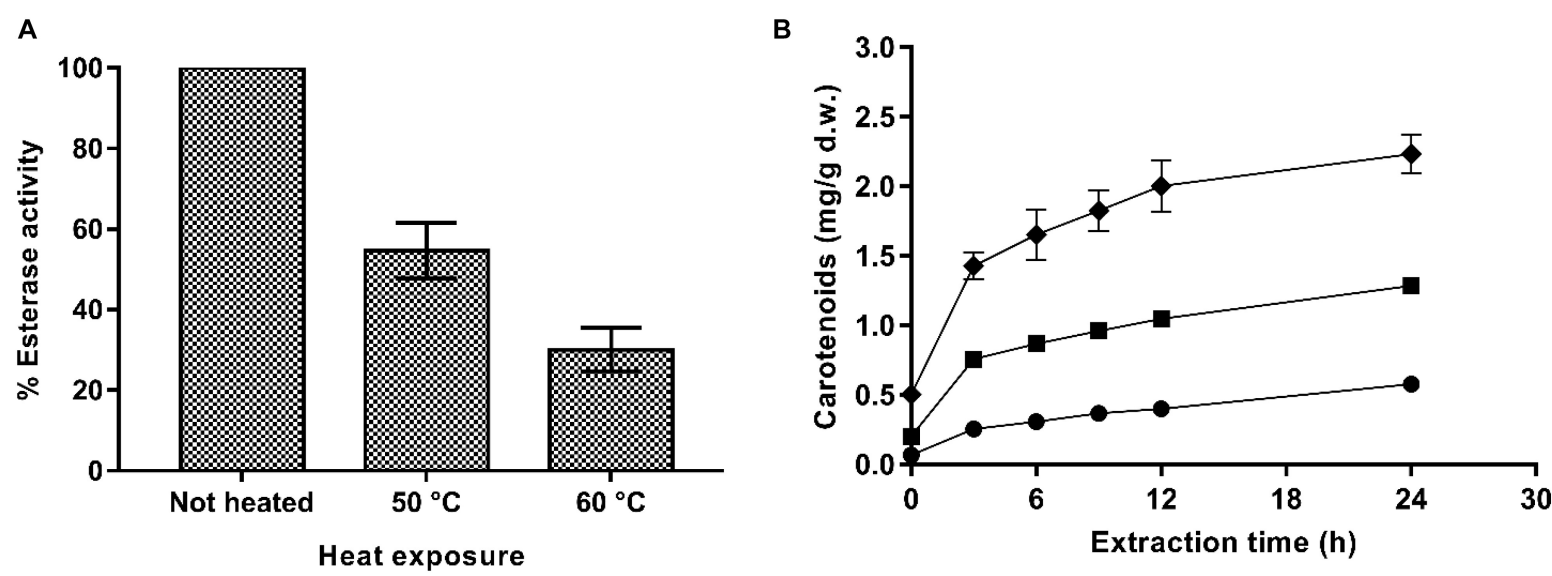

FIGURE 6 | (A) Percentage of esterase activity remaining in the supernatant containing PEF-treated (20 kV/cm, $135 \mu \mathrm{s})$ X. dendrorhous ATCC 74219 cells after 5 min of heating at 50 and $60^{\circ} \mathrm{C}$. (B) Effect of the thermal inactivation of esterase on ethanolic extraction of carotenoids from and $X$. dendrorhous ATCC 74219 after $12 \mathrm{~h}$ of incubation in buffer of $\mathrm{pH} 7.0$ : unheated $(\checkmark)$ and heat-treated at $50^{\circ} \mathrm{C}(\boldsymbol{\square}), 60^{\circ} \mathrm{C}(\boldsymbol{})$. The $100 \%$ of esterase activity represent the maximum esterase activity quantified in the unheated PEF-treated cells supernatant.

electroporation caused by PEF. However, despite the higher enzymatic activity detected in the ATCC 74219 strain, the fact that esterase activity was detected during the aqueous incubation of both strains makes unclear whether the esterase enzyme is involved in the mechanisms of the extraction assisted by PEF.

Thus, to confirm this hypothesis, an experiment consisting of exposing the PEF-treated X. dendrorhous ATCC 74219 cells to a heat treatment before incubation in buffer of $\mathrm{pH} 7.0$ to denaturalize esterase enzyme was conducted. Percentages of esterase activity remaining in the supernatant containing PEFtreated cells treated for $5 \mathrm{~min}$ at 50 and $60^{\circ} \mathrm{C}$ after $12 \mathrm{~h}$ of incubation in buffer are shown in Figure 6A. Extraction curves of carotenoids from PEF-treated cells treated at 50 and $60^{\circ} \mathrm{C}$ after $12 \mathrm{~h}$ of buffer incubation and subsequent extraction in ethanol are compared with the carotenoid extraction from unheated cells in Figure 6B.

Results showed that the thermal treatment effectively inactivated the esterase enzyme, decreasing its activity in the supernatant by 50 and $75 \%$ for the treatments applied at 50 and $60^{\circ} \mathrm{C}$, respectively. Accordingly, carotenoid recovery was much lower for the heat-treated PEF-treated cells along all the extraction process. After $24 \mathrm{~h}$ of extraction, a decrease by 42 and $72 \%$ in the extraction yield was observed for thermally treated cells at 50 or $60^{\circ} \mathrm{C}$, respectively.

The correlation between carotenoid extraction yield and the esterase activity reduction in the supernatant containing PEFthermally treated cells would confirm that PEF assisted extraction of carotenoids was a process mediated by esterases at the evaluated conditions at least for from $X$. dendrorhous ATCC 74219. However, these results are in contrast to those observed in $X$. dendrorhous CECT 11028, where the esterase activity detected in the PEF-treated cells were not correlated with carotenoids extraction.

An optical microscopy comparation after $12 \mathrm{~h}$ of incubation at $25^{\circ} \mathrm{C}$ in a buffer of pH 7.0 of untreated and PEF-treated cells of the two strains of $X$. dendrorhous is shown in Figure 7. It was observed at the beginning of the incubation (data not shown), that carotenoids were located in the cytoplasm into droplet structures. Incubation for $12 \mathrm{~h}$ did not cause any significant change in the untreated cells of both strains. Furthermore, optical observation confirmed the higher carotenoid production by X. dendrorhous ATCC 74219 (3.5 $\pm 0.15 \mathrm{mg} / \mathrm{g}$ d.w.) compared to $X$. dendrorhous CECT 11028 (0.36 $\pm 0.02 \mathrm{mg} / \mathrm{g}$ d.w.). While in the hyper-producer most of the observed droplets corresponded to carotenoids in the other strain most droplets correspond to lipids.

On the other hand, significant differences were observed between the two strains when the PEF-treated cells were incubated in $\mathrm{pH} 7.0$ buffer. While complete droplet disintegration was observed in $X$. dendrorhous ATCC 74219, in the case of the strain CECT 11028 incubation of the PEF-treated cells clearly led to lipid droplet fusion in a bigger droplet. In both cases, the changes in the droplets observed after incubation could be mediated by esterases, which activity was triggered by the electroporation of the cell membrane of the yeast. These observations seem to indicate that ethanol was only effective for extracting those intracellular carotenoids that are free in the cytoplasm. However, ethanolic extraction was ineffective when the carotenoids were located into droplet structures such as in untreated or PEF-treated cells before incubation in both strains or as in the CECT 11028 strain after $12 \mathrm{~h}$ of incubation.

\section{DISCUSSION}

Pulsed electric fields-assisted extraction of intracellular compounds is associated with the improvement of mass transfer processes trough cytoplasmic membrane once its permeability has been modified by electroporation (Puértolas et al., 2012). It is well known that irreversible modification of the selective permeability of the cytoplasmic membrane leads to the microbial inactivation (Pillet et al., 2016). Therefore, in order 

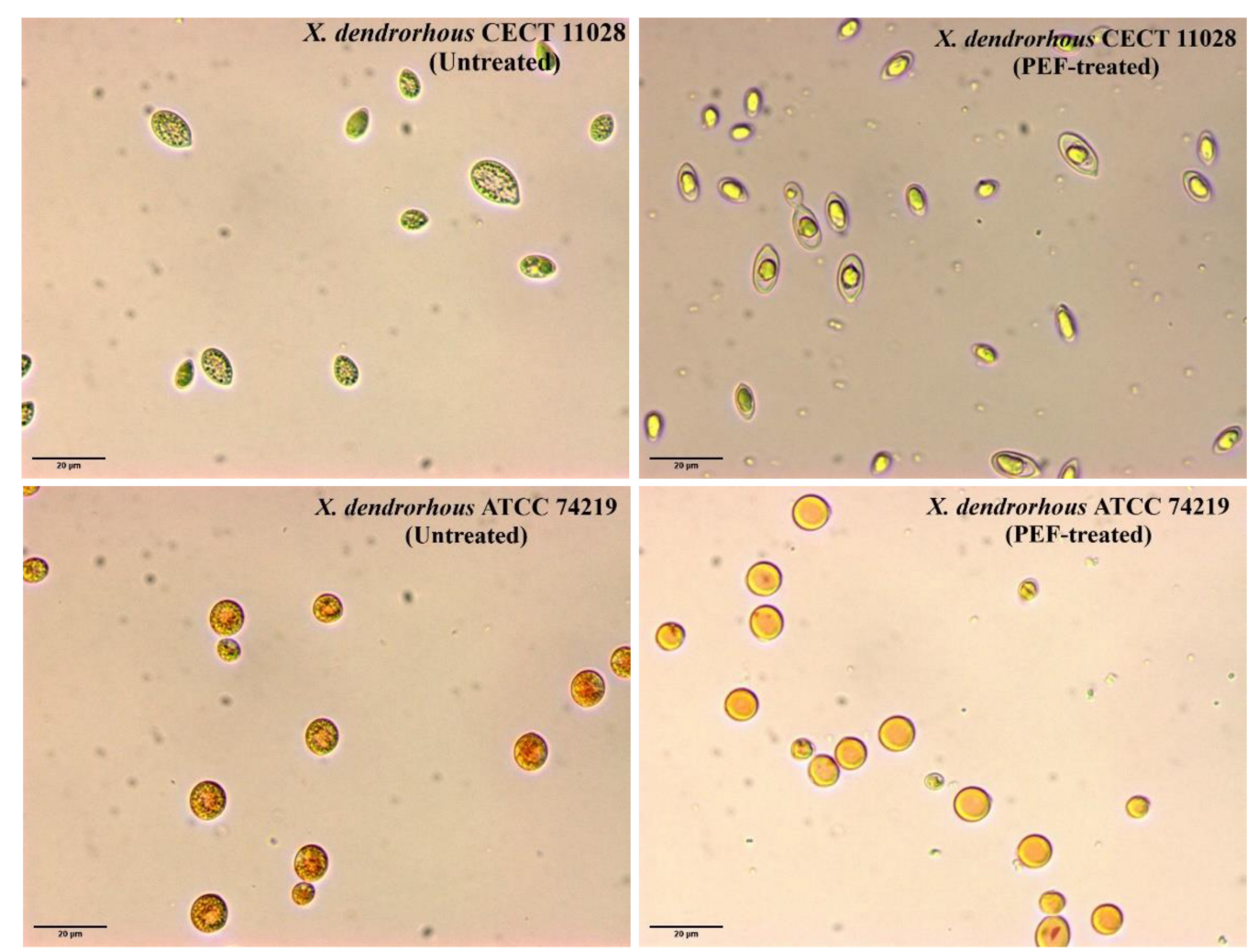

FIGURE 7 | Optical microscopy observation (600x) of untreated and PEF-treated of $X$. dendrorhous CECT 11028 and $X$. dendrorhous ATCC 74219 cells after $12 \mathrm{~h}$ of incubation at $25^{\circ} \mathrm{C}$ in a buffer of $\mathrm{pH} 7$.

to identify the appropriate range of treatment conditions for irreversible electroporation, the sensitivity of the two strains to PEF treatments of different intensity was investigated (Figure 1). $X$. dendrorhous ATCC 74219 strain was more PEF resistant than the strain CECT 11028 and compared with other yeast, both strains showed lower sensitivity to PEF (Aronsson et al., 2005; Martínez et al., 2016). Currently, the influence of the cell envelopes surrounding the cytoplasmatic membrane on electroporation by PEF is unclear, but it has suggested that cell wall could influence the sensitivity to PEF (Aronsson et al., 2005; García et al., 2007). The highest PEF resistance could be related with the fact that oleaginous yeasts such as of $X$. dendrorhous have a higher fraction of chitin and/or mannan in the cell wall compared to non-oleaginous species that contribute to the rigidity and resistance to cell lysis (Khot et al., 2020). This rigidity and resistance to cell lysis should be higher in the ATCC 74219 strain to contain around 10 times more of carotenoids than those contained in the CECT 11028.

A small proportion of inactivated $X$. dendrorhous cells were impermeable to PI after application of mild intensity PEF treatments that caused low inactivation. This observation, previously reported by other authors, suggests that in these cells, the pore resealing is a physical process rather than a process with biosynthetic requirements (Martínez et al., 2018). Therefore, quantification of the proportion of inactivated cells is a suitable index for estimation of the number of irreversible electroporation cells when the inactivation is higher of a given value, that in the case of the strains of $X$. dendrorhous investigated was around $70 \%$.

In order to develop a sustainable and cost-efficient overall bioprocess, carotenoids were extracted from wet biomass of $X$. dendrorhous (avoiding too high costs derived from drying) and ethanol was used as a solvent. Ethanol is a polar watersoluble solvent that is less toxic and greener than others used for extracting lipophilic compounds such as hexane, dichloromethane or chloroform (Saini and Keum, 2018).

The water solubility of ethanol in water should allow its diffusion through the cell wall and cell membrane and reaching the carotenoids located in the cytoplasm of $X$. dendrorhous. However, ethanol was inefficient for extracting carotenoids from the two investigated strains, even when around 80\% of the population cells were irreversibly electroporated. This observation suggested that ethanol was not able to dissolve the carotenoids located in the droplets.

As it was previously mentioned, it was suggested that PEF triggers an enzymatic process that enables the yeast autolysis, which then allows the extraction of the intracellular compounds. Thus, the subsequent studies aimed at verifying this hypothesis and increasing the recovery yields of carotenoids. By evaluating the incubation process in the buffer solution, it was shown that ethanol was effective for extracting carotenoids from PEF-treated cells of $X$. dendrorhous ATCC 74219. Recently, several authors 
have reported that an aqueous incubation period after PEF treatment increased the extraction yield of carotenoids, lipids and proteins from microalgae and yeasts (Luengo et al., 2014; Dimopoulos et al., 2018; Martínez et al., 2018, 2019; Silve et al., 2018; Scherer et al., 2019). This improvement in the extraction has been attributed to enzyme-driven processes triggered by PEF that occur during the aqueous incubation period.

The efficiency of ethanol for extracting carotenoids from PEFtreated X. dendrorhous ATCC 74219 after buffer incubation was dependent on the proportion of cells electroporated. Increments in the electric field strength that lead to a high proportion of electroporated cells result in a higher extraction until $20 \mathrm{kV} / \mathrm{cm}$.

HPLC quantification of astaxanthin from ethanolic extracts obtained with different PEF treatment intensities (Table 1) showed that up to $84 \%(2.06 \pm 0.02 \mathrm{mg} / \mathrm{g}$ d.w. $)$ of total carotenoids extracted corresponded to trans-astaxanthin. This proportion agrees with values reported in the literature for other $X$. dendrorhous strains (Johnson and Lewis, 1979; de la Fuente et al., 2010; Schmidt et al., 2011). The high yield of transastaxanthin $(2.06 \pm 0.02 \mathrm{mg} / \mathrm{g}$ d.w.) obtained in this study from $X$. dendrorhous ATCC 74219 was in range to other reported yields obtained for X. dendrorhous ATCC 74219. Amado and Vázquez (2015) reported a maximum astaxanthin specific concentration of $2.0 \mathrm{mg} / \mathrm{g} \mathrm{d.w}$. by culturing the same strains of $X$. dendrorhous ATCC 74219 in a low-cost media designed from marine byproducts, while Stoklosa et al. (2018) reported $2.49 \mathrm{mg} / \mathrm{g}$ d.w. specific astaxanthin production by culturing the same strain in sweet sorghum juice.

The results related with the evaluation of enzymatic activities seemed to confirm that the enzymatic esterase activity triggered by PEF mediates the effective ethanolic extraction of carotenoids from PEF-treated X. dendrorhous ATCC 74219 at the evaluated conditions. The uncontrolled molecular transport thought the electroporated cytoplasmic membrane of the yeast could decrease the osmotic pressure of the cytoplasm as a consequence of water inlet, causing the plasmolysis of lysosomes and the liberation of hydrolytic enzymes such as esterases. These esterases could hydrolyze the triacylglycerols of lipid droplets resulting in the loss of their structure and the subsequent carotenoid release. Once the carotenoids are free in the cytoplasm, they could be dissolved in ethanol and the complex carotenoid-solvent could diffuse across the cell membrane driven by a concentration gradient. The presence of esterase activity in the supernatant containing PEF-treated cells during buffer incubation and the lower carotenoid extraction yield when esterase activity was reduced by heating, supported such hypothesis. Furthermore, the lack of effectivity in the carotenoid extraction when PEFtreated cells were immediately incubated in ethanol could be explained for esterase denaturation when exposed to high concentrations of ethanol.

Although esterase activity was also detected in the electroporated X. dendrorhous CECT 11028, the inefficiency of ethanol for extracting the carotenoids could be related to the changes observed in the cytoplasm of the cells after incubation (Figure 7). As it has been previously described for the microalga Chlamydomonas reinhardtii, the aqueous incubation of the PEFtreated cells clearly led to the fusion of the lipid droplets in a big globule (Bodénès et al., 2016; Bensalem et al., 2018). In addition, this big globule of lipids might content the synthesized carotenoids by the strain CECT 11028 because neither free carotenoids nor carotenoid droplets were observed in the cytoplasm after fusion. Lipid fusion of the lipid droplets did not occur in the strain ATCC 74219 probably because, as it is observed in Figure 7 in this hyper-producer strain, most of the droplets contained in the cytoplasm correspond to carotenoids.

Due to polarity properties of ethanol, this solvent was unable to dissolve the single large lipid droplet, mainly constituted for neutral lipids with long hydrophobic fatty acid chains (Halim et al., 2012). Therefore, using a mixture of polar and non-polar solvents might allow dissolving this lipid structure, or the rupture of the cell wall should be required for carotenoid extraction from the CECT 11028 strain (Bensalem et al., 2018).

\section{CONCLUSION}

This research has demonstrated that application of PEF treatment and subsequent aqueous incubation of fresh biomass of $X$. dendrorhous ATCC 74219 allowed the ethanolic extraction of $70 \%$ of the total carotenoids which up to $84 \%$ correspond to trans-astaxanthin. The effective extraction depended on the proportion of electroporated cells and the hydrolytic activity of the enzyme esterase during incubation triggered by PEF. The ineffective extraction of carotenoids from $X$. dendrorhous CECT 11028 seemed to be related to the inability of ethanol to dissolve the lipids structure containing carotenoids.

In order to establish the procedure developed in this study as a sustainable method with low environmental impact for extraction of trans-astaxanthin, further studies are required to optimize PEF treatment, enzymatic activity and extraction conditions for improving extraction yields with the lowest energetic costs.

\section{DATA AVAILABILITY STATEMENT}

The raw data supporting the conclusions of this article will be made available by the authors, without undue reservation.

\section{AUTHOR CONTRIBUTIONS}

DA-M, JM, and JR: conception and design of the study. DAM, CD, and JMM: acquisition of data. DA-M, LM-O, and JR: analysis and interpretation of the data. DA-M and JMM: drafting of the manuscript. LM-O, JM, and JR: critical revision of the manuscript. All authors contributed to the article and approved the submitted version.

\section{FUNDING}

DA-M acknowledges CONACyT-México for the financial support provided for conducting the Ph.D. (486828-2017). At the Universidad de Zaragoza and Universidad Autónoma de Coahuila by the scientific support. 


\section{REFERENCES}

Amado, I. R., and Vázquez, J. A. (2015). Mussel processing wastewater: a lowcost substrate for the production of astaxanthin by Xanthophyllomyces dendrorhous. Microb. Cell Fact. 14:177. doi: 10.1186/s12934-0150375-5

Aronsson, K., Rönner, U., and Borch, E. (2005). Inactivation of Escherichia coli, Listeria innocua and Saccharomyces cerevisiae in relation to membrane permeabilization and subsequent leakage of intracellular compounds due to pulsed electric field processing. Intern. J. Food Microbiol. 99, 19-32. doi: 10. 1016/j.ijfoodmicro.2004.07.012

Bensalem, S., Lopes, F., Bodénès, P., Pareau, D., Français, O., and Le Pioufle, B. (2018). Understanding the mechanisms of lipid extraction from microalga Chlamydomonas reinhardtii after electrical field solicitations and mechanical stress within a microfluidic device. Bioresour. Technol. 257, 129-136. doi: 10. 1016/j.biortech.2018.01.139

Bodénès, P., Lopes, F., Pareau, D., Français, O., and Le Pioufle, B. (2016). Microdevice for studying the in situ permeabilization and characterization of Chlamydomonas reinhardtii in lipid accumulation phase. Algal Res. 16, 357-367. doi: 10.1016/j.algal.2016.03.023

Capelli, B., Bagchi, D., and Cysewski, G. R. (2013). Synthetic astaxanthin is significantly inferior to algal-based astaxanthin as an antioxidant and may not be suitable as a human nutraceutical supplement. Nutrafoods 12, 145-152. doi: 10.1007/s13749-013-0051-5

Chittapun, S., Jonjaroen, V., Khumrangsee, K., and Charoenrat, T. (2020). Cphycocyanin extraction from two freshwater cyanobacteria by freeze thaw and pulsed electric field techniques to improve extraction efficiency and purity. Algal Res. 46:101789. doi: 10.1016/j.algal.2020.101789

Choi, S., Kim, J., Park, Y., Kim, Y., and Chang, H. (2007). An efficient method for the extraction of astaxanthin from the red yeast Xanthophyllomyces dendrorhous. J. Microbiol. Biotech. 17, 847-852.

de la Fuente, J. L., Rodríguez-Sáiz, M., Schleissner, C., Díez, B., Peiro, E., and Barredo, J. L. (2010). High-titer production of astaxanthin by the semiindustrial fermentation of Xanthophyllomyces dendrorhous. J. Biotechnol. 148, 144-146. doi: 10.1016/j.jbiotec.2010.05.004

Dimopoulos, G., Stefanou, N., Andreou, V., and Taoukis, P. (2018). Effect of pulsed electric fields on the production of yeast extract by autolysis. Innovat. Food Sci. Emerg. Technol. 48, 287-295. doi: 10.1016/j.ifset.2018.07.005

Fakhri, S., Abbaszadeh, F., Dargahi, L., and Jorjani, M. (2018). Astaxanthin: a mechanistic review on its biological activities and health benefits. Pharmacol. Res. 136, 1-20. doi: 10.1016/j.phrs.2018.08.012

Ganeva, V., Galutzov, B., and Teissié, J. (2003). High yield electroextraction of proteins from yeast by a flow process. Analyt. Biochem. 315, 77-84. doi: 10.1016/ S0003-2697(02)00699-1

García, D., Gómez, N., Mañas, P., Raso, J., and Pagán, R. (2007). Pulsed electric fields cause bacterial envelopes permeabilization depending on the treatment intensity, the treatment medium $\mathrm{pH}$ and the microorganism investigated. Intern. J. Food Microbiol. 113, 219-227. doi: 10.1016/j.ijfoodmicro.2006.07.007

García-Gonzalo D., and Pagán R. (2017). "Detection of electroporation in microbial cells: techniques and procedures," in Handbook of Electroporation, ed. D. Miklavcic (Cham: Springer). doi: 10.1007/978-3-319-26779-1

Gilham, D., and Lehner, R. (2005). Techniques to measure lipase and esterase activity in vitro. Methods 36, 139-147. doi: 10.1016/j.ymeth.2004.11.003

Gogate, P. R., and Nadar, S. G. (2015). Ultrasound-assisted intensification of extraction of astaxanthin from Phaffia rhodozyma. Indian Chem. Eng. 57, 240-255. doi: 10.1080/00194506.2015.1026947

Halim, R., Danquah, M. K., and Webley, P. A. (2012). Extraction of oil from microalgae for biodiesel production: a review. Biotechnol. Adv. 30, 709-732. doi: 10.1016/j.biotechadv.2012.01.001

Hasan, M., Azhar, M., Nangia, H., Bhatt, P. C., and Panda, B. P. (2016). Influence of high-pressure homogenization, ultrasonication, and supercritical fluid on free astaxanthin extraction from $\beta$-glucanase-treated Phaffia rhodozyma cells. Prep. Biochem. Biotechnol. 46, 116-122. doi: 10.1080/10826068.2014.99 5807

Higuera-Ciapara, I., Felix-Valenzuela, L., and Goycoolea, F. M. (2006). Astaxanthin: a review of its chemistry and applications. Crit. Rev. Food Sci. Nutr. 46, 185-196. doi: 10.1080/10408690590957188
Jacobson, G. K., Jolly, S. O., Sedmak, J. J., Skatrud, T. J., and Wasileski, J. M. (1995). Astaxanthin Over-Producing Strains Of Phaffia rhodozyma. U.S. Patent No. 5,466,599. Washington, DC: U.S. Patent and Trademark Office.

Johnson, E. A., and Gil-Hwan, A. (1991). Astaxanthin from microbial sources. Crit. Rev. Biotechnol. 11, 297-326. doi: 10.3109/07388559109040622

Johnson, E. A., and Lewis, M. J. (1979). Astaxanthin formation by the yeast Phaffia rhodozyma. Microbiology 115, 173-183. doi: 10.1099/00221287-115-1-173

Khot, M., Raut, G., Ghosh, D., Alarcón-Vivero, M., Contreras, D., and Ravikumar, A. (2020). Lipid recovery from oleaginous yeasts: perspectives and challenges for industrial applications. Fuel 259:116292. doi: 10.1016/j.fuel.2019.116292

Kotnik, T., Frey, W., Sack, M., Meglič, S. H., Peterka, M., and Miklavčič, D. (2015). Electroporation-based applications in biotechnology. Trends Biotechnol. 33, 480-488. doi: 10.1016/j.tibtech.2015.06.002

Kurihara, H., Koda, H., Asami, S., Kiso, Y., and Tanaka, T. (2002). Contribution of the antioxidative property of astaxanthin to its protective effect on the promotion of cancer metastasis in mice treated with restraint stress. Life Sci. 70, 2509-2520. doi: 10.1016/S0024-3205(02)01522-9

Leonhardt, L., Käferböck, A., Smetana, S., de Vos, R., Toepfl, S., and Parniakov, O. (2020). Bio-refinery of Chlorella sorokiniana with pulsed electric field pretreatment. Bioresour. Technol. 301:122743. doi: 10.1016/j.biortech.2020.12274

Li, J., Zhu, D., Niu, J., Shen, S., and Wang, G. (2011). An economic assessment of astaxanthin production by large scale cultivation of Haematococcus pluvialis. Biotechnol. Adv. 29, 568-574. doi: 10.1016/j.biotechadv.2011.04.001

Luengo, E., Condón-Abanto, S., Álvarez, I., and Raso, J. (2014). Effect of pulsed electric field treatments on permeabilization and extraction of pigments from Chlorella vulgaris. J. Memb. Biol. 247, 1269-1277. doi: 10.1007/s00232-0149688-2

Martínez, J. M., Cebrián, G., Álvarez, I., and Raso, J. (2016). Release of mannoproteins during Saccharomyces cerevisiae autolysis induced by pulsed electric field. Front. Microbiol. 7:1435. doi: 10.3389/fmicb.2016.01435

Martínez, J. M., Delso, C., Angulo, J., Álvarez, I., and Raso, J. (2018). Pulsed electric field-assisted extraction of carotenoids from fresh biomass of Rhodotorula glutinis. Innovat. Food Sci. Emerg. Technol. 47, 421-427. doi: 10.1016/j.ifset. 2018.04.012

Martínez, J. M., Gojkovic, Z., Ferro, L., Maza, M., Álvarez, I., Raso, J., et al. (2019). Use of pulsed electric field permeabilization to extract astaxanthin from the Nordic microalga Haematococcus pluvialis. Bioresour. Technol. 289:121694. doi: 10.1016/j.biortech.2019.121694

Michelon, M., de Borba, T. D. M., da Silva Rafael, R., Burkert, C. A. V., and de Medeiros Burkert, J. F. (2012). Extraction of carotenoids from Phaffia rhodozyma: a comparison between different techniques of cell disruption. Food Sci. Biotechnol. 21, 1-8. doi: 10.1007/s10068-012-0001-9

Molino, A., Rimauro, J., Casella, P., Cerbone, A., Larocca, V., Chianese, S., et al. (2018). Extraction of astaxanthin from microalga Haematococcus pluvialis in red phase by using generally recognized as safe solvents and accelerated extraction. J. Biotechnol. 283, 51-61. doi: 10.1016/j.jbiotec.2018.07.010

Nagendraprabhu, P., and Sudhandiran, G. (2011). Astaxanthin inhibits tumor invasion by decreasing extracellular matrix production and induces apoptosis in experimental rat colon carcinogenesis by modulating the expressions of ERK2, NFkB and COX-2. Invest. New Drugs 29, 207-224. doi: 10.1007/s10637-0099342-5

Ni, H., Chen, Q. H., He, G. Q., Wu, G. B., and Yang, Y. F. (2008). Optimization of acidic extraction of astaxanthin from Phaffia rhodozyma. J. Zhejiang Univ. Sci. B 9, 51-59. doi: 10.1631/jzus.B061261

Ohgami, K., Shiratori, K., Kotake, S., Nishida, T., Mizuki, N., Yazawa, K., et al. (2003). Effects of astaxanthin on lipopolysaccharide-induced inflammation in vitro and in vivo. Invest. Ophthalmol. Vis. Sci. 44, 2694-2701. doi: 10.1167/iovs. 02-0822

Pashkow, F. J., Watumull, D. G., and Campbell, C. L. (2008). Astaxanthin: a novel potential treatment for oxidative stress and inflammation in cardiovascular disease. Am. J. Cardiol. 101, S58-S68. doi: 10.1016/j.amjcard.2008.02.010

Peng, J., Yuan, J. P., and Wang, J. H. (2012). Effect of diets supplemented with different sources of astaxanthin on the gonad of the sea urchin Anthocidaris crassispina. Nutrients 4, 922-934. doi: 10.3390/nu4080922

Pillet, F., Formosa-Dague, C., Baaziz, H., Dague, E., and Rols, M. P. (2016). Cell wall as a target for bacteria inactivation by pulsed electric fields. Sci. Rep. 6:19778. doi: 10.1038/srep19778 
Puértolas, E., Luengo, E., Álvarez, I., and Raso, J. (2012). Improving mass transfer to soften tissues by pulsed electric fields: fundamentals and applications. Annu. Rev. Food Sci. Technol. 3, 263-282. doi: 10.1146/annurev-food-022811-101208

Saini, R. K., and Keum, Y. S. (2018). Carotenoid extraction methods: a review of recent developments. Food Chem. 240, 90-103. doi: 10.1016/j.foodchem.2017. 07.099

Saldaña, G., Puértolas, E., Álvarez, I., Meneses, N., Knorr, D., and Raso, J. (2010). Evaluation of a static treatment chamber to investigate kinetics of microbial inactivation by pulsed electric fields at different temperatures at quasi-isothermal conditions. J. Food Eng. 100, 349-356. doi: 10.1016/j.jfoodeng. 2010.04.021

Scherer, D., Krust, D., Frey, W., Mueller, G., Nick, P., and Gusbeth, C. (2019). Pulsed electric field (PEF)-assisted protein recovery from Chlorella vulgaris is mediated by an enzymatic process after cell death. Algal Res. 41:101536. doi: 10.1016/j.algal.2019.101536

Schmidt, I., Schewe, H., Gassel, S., Jin, C., Buckingham, J., Hümbelin, M., et al. (2011). Biotechnological production of astaxanthin with Phaffia rhodozyma/Xanthophyllomyces dendrorhous. Appl. Microbiol. Biotechnol. 89, 555-571. doi: 10.1007/s00253-010-2976-6

Sedmak, J. J., Weerasinghe, D. K., and Jolly, S. O. (1990). Extraction and quantitation of astaxanthin from Phaffia rhodozyma. Biotechnol. Techn. 4, 107-112. doi: 10.1007/BF00163282

Shah, M., Mahfuzur, R., Liang, Y., Cheng, J. J., and Daroch, M. (2016). Astaxanthinproducing green microalga Haematococcus pluvialis: from single cell to high value commercial products. Front. Plant Sci. 7:531. doi: 10.3389/fpls.2016. 00531

Silve, A., Kian, C. B., Papachristou, I., Kubisch, C., Nazarova, N., Wüstner, R., et al. (2018). Incubation time after pulsed electric field treatment of microalgae enhances the efficiency of extraction processes and enables the reduction of specific treatment energy. Bioresour. Technol. 269, 179-187. doi: 10.1016/j. biortech.2018.08.060

Stoklosa, R. J., Johnston, D. B., and Nghiem, N. P. (2018). Utilization of sweet sorghum juice for the production of astaxanthin as a biorefinery co-product by Phaffia rhodozyma. ACS Sustain. Chem. Eng. 6, 3124-3134. doi: 10.1021/ acssuschemeng.7b03154

Uchiyama, K., Naito, Y., Hasegawa, G., Nakamura, N., Takahashi, J., and Yoshikawa, T. (2002). Astaxanthin protects $\beta$-cells against glucose toxicity in diabetic db/db mice. Redox Rep. 7, 290-293. doi: 10.1179/13510000212500 0811
Urnau, L., Colet, R., Soares, V. F., Franceschi, E., Valduga, E., and Steffens, C. (2018). Extraction of carotenoids from Xanthophyllomyces dendrorhous using ultrasound-assisted and chemical cell disruption methods. Can. J. Chem. Eng. 96, 1377-1381. doi: 10.1002/cjce.23046

Villegas-Méndez, M. Á, Aguilar-Machado, D. E., Balagurusamy, N., Montañez, J., and Morales-Oyervides, L. (2019). Agro-industrial wastes for the synthesis of carotenoids by Xanthophyllomyces dendrorhous: mesquite pods-based medium design and optimization. Biochem. Eng. J. 150:107260. doi: 10.1016/j.bej.2019. 107260

Visser, H., Van Ooyen, A. J., and Verdoes, J. C. (2003). Metabolic engineering of the astaxanthin-biosynthetic pathway of Xanthophyllomyces dendrorhous. FEMS Yeast Res. 4, 221-231. doi: 10.1016/S1567-1356(03)0 0158-2

Wu, S., Li, W., Zhou, W., Zhan, Y., Hu, C., Zhuang, J., et al. (2018). Large-scale one-step synthesis of carbon dots from yeast extract powder and construction of carbon dots/PVA fluorescent shape memory material. Adv. Opt. Mater. 6:1701150. doi: 10.1002/adom.201701150

Yuan, J. P., and Chen, F. (1997). Identification of astaxanthin isomers in Haematococcus lacustris by HPLC-photodiode array detection. Biotechnol. Techn. 11, 455-459. doi: 10.1023/A:1018441411746

Zhao, T., Yan, X., Sun, L., Yang, T., Hu, X., He, Z., et al. (2019). Research progress on extraction, biological activities and delivery systems of natural astaxanthin. Trends Food Sci. Technol. 91, 354-361. doi: 10.1016/j.tifs.2019.07.014

Zhuang, Y., Jiang, G. L., and Zhu, M. J. (2020). Atmospheric and room temperature plasma mutagenesis and astaxanthin production from sugarcane bagasse hydrolysate by Phaffia rhodozyma mutant Y1. Process Biochem. 91, 330-338. doi: 10.1016/j.procbio.2020.01.003

Conflict of Interest: The authors declare that the research was conducted in the absence of any commercial or financial relationships that could be construed as a potential conflict of interest.

Copyright (c) 2020 Aguilar-Machado, Delso, Martinez, Morales-Oyervides, Montañez and Raso. This is an open-access article distributed under the terms of the Creative Commons Attribution License (CC BY). The use, distribution or reproduction in other forums is permitted, provided the original author(s) and the copyright owner(s) are credited and that the original publication in this journal is cited, in accordance with accepted academic practice. No use, distribution or reproduction is permitted which does not comply with these terms. 


\section{APPENDIX}

A

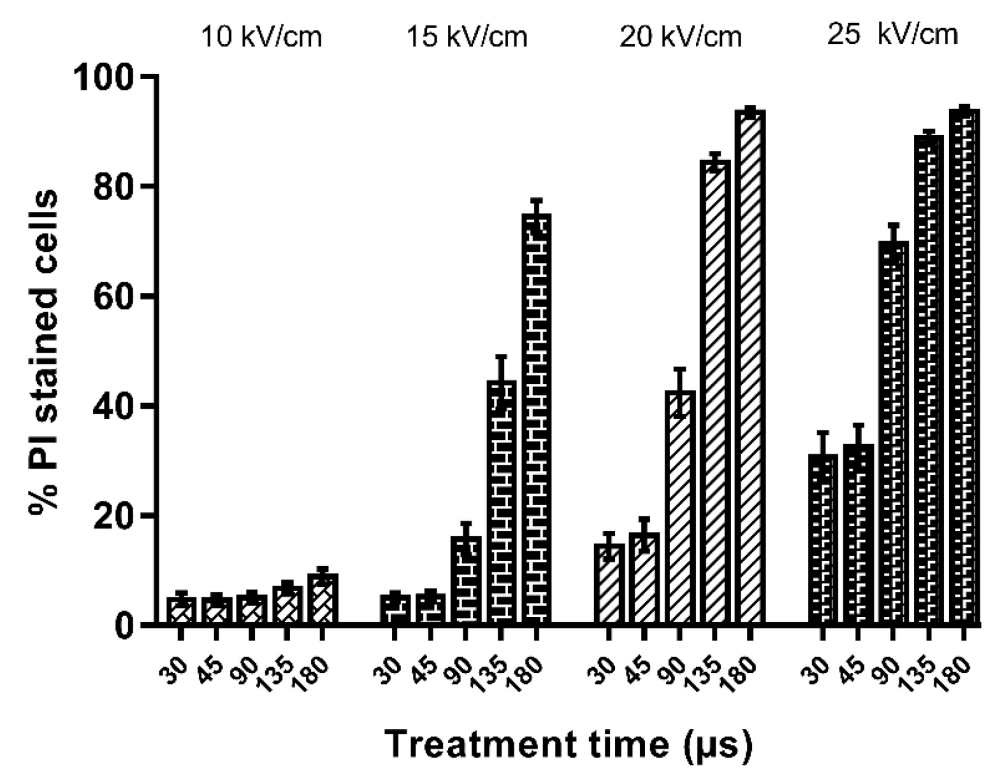

B

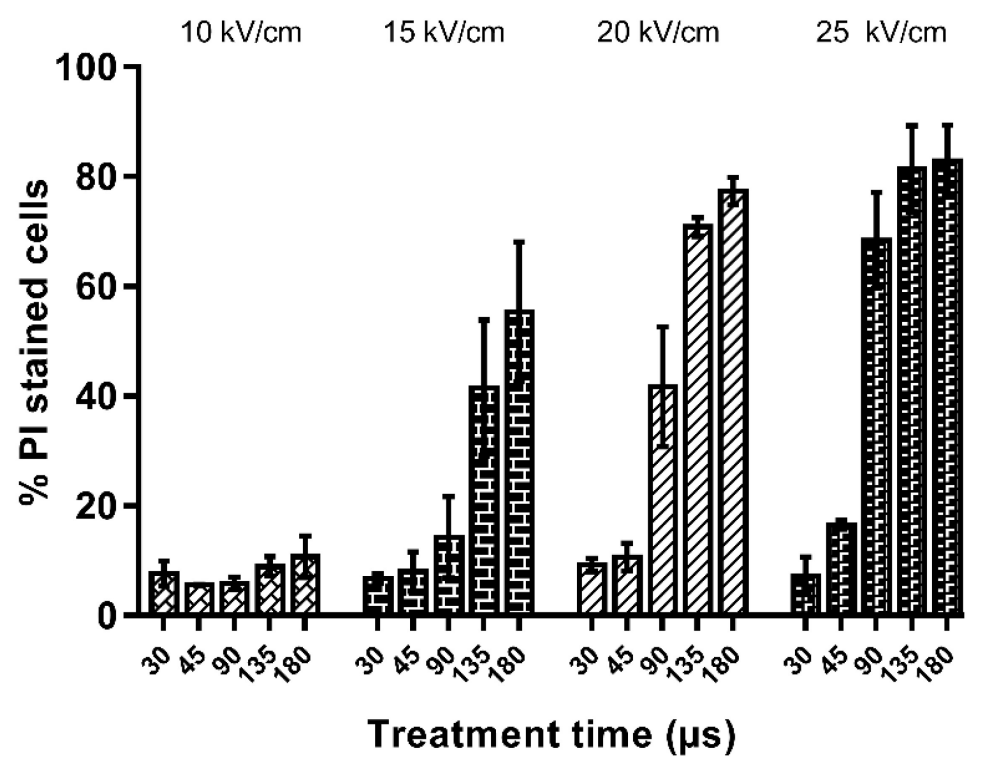

FIGURE A1 | Percentage of propidium iodide uptake by X. dendrorhous CECT 11028 (A) and X. dendrorhous ATCC 74219 (B) after PEF treatments with different electric field strength and treatment time. 